\title{
Segmental Darier's disease: a presentation of difficult diagnosis*
}

\author{
Paula Mota Medeiros ${ }^{1}$ \\ Jeniffer Muñoz Trujillo ${ }^{1}$ \\ Paula Carolina Pessanha de Faria ${ }^{1}$
}

\author{
Natália Ribeiro de Magal hães Alves ${ }^{1}$ \\ Cássia Camarinha da Silva ${ }^{1}$ \\ Roberto Souto da Silva ${ }^{1}$
}

DOI: http:/ / dx.doi.org/ 10.1590/ abd1806-4841.20153581

\begin{abstract}
Darier's disease is a rare autosomal dominant genodermatosis. It has an estimated prevalence of 1 in 55,000 to 100,000 individuals, regardless of gender. It is characterized by multiple keratotic papules on the seborrheic areas of the trunk, scalp, forehead and flexures, and the clinical picture is worsened by heat, sun exposure, perspiration and mechanical trauma. Histopathology observed loss of epithelial adhesion and abnormal keratinization. About $10 \%$ of cases present in the localized form of the disease. We report a case of segmental Darier's Disease Type I and discuss the main characteristics of this condition.
\end{abstract}

Keywords: Darier's Disease; M osaicism; Skin diseases; Skin diseases, genetic

\section{INTRODUCTION}

Darier's disease (Darier-White disease or follicular keratosis) was described by Darier and White in 1889. ${ }^{1}$ It is a rare genodermatosis of autosomal dominant inheritance, with high penetrance and variable expressivity.1,2

The estimated prevalence of Darier's disease is 1 in 55,000 to 100,000 individuals. Men and women are equally affected. ${ }^{3}$ The first signs of the condition appear between 6 and 20 years of age. ${ }^{3}$

This disease is a consequence of spontaneous or hereditary mutations in the gene that codifies the endoplasmic reticulum calcium-dependent ATPase (product of protein SERCA2), located in chromosome 12, in region $12 q 23-q 24 .{ }^{1}$ These alterations modify the efficient processing of proteins necessary for cellular adhesion, leading to defective organization of tonofilaments with manifestations of acantholysis and dyskeratosis. $^{2}$
Patients develop keratotic papules which may coalesce in plaques in seborrheic areas of the trunk, scal $p$, forehead and flexures. Thelesions may havebad odor, especially in flexural areas, and be prone to secondary infection, which leads to clinical exacerbation and worsening of the odor. The presence of keratotic papules is common on palms and soles, in addition to ungual abnormalities, including erythematous and/ or white longitudinal lines, fragility of nails, which tend to break distally in a " $\mathrm{V}$ " shape and subungual keratosis. These alterations in the extremities may be the first sign of widespread disease. Hypochromic papules may be present in mucosae. ${ }^{3}$

Around $10 \%$ of DD cases present localized lesions, which is a rarer clinical presentation, with 40 cases described in English literature. ${ }^{3-5}$ This pattern was reported for the first time in 1906. Since then, several variants of the localized disease were described: unilateral, linear, segmental or zosteriform. ${ }^{3,4}$

\footnotetext{
Received on 27.03.2014

A pproved by the Advisory Board and accepted for publication on 19.05.2014

Work performed at Hospital Universitário Pedro Ernesto da Universidade do Estado do Rio de Janeiro (HUPE - UERJ) - Rio de Janeiro (RJ), Brazil. Financial Support: None.

Conflict of Interest: N one.

1 Universidade do Estado do Rio de Janeiro (UERJ) - Rio de Janeiro, Brazil.
}

(C2015 by A nais Brasileiros de Dermatologia 
Two phenotypes are recognized in the localized disease. Type I is characterized by unilateral distribution along the Blaschko lines. In type II variant, patients present widespread disease with localized areas of more severe involvement. ${ }^{2,4}$

We report a case of type I segmental DD, with lesions confined to the right lower limb of the patient, with histopathological confirm ation.

\section{CASE REPORT}

Female patient, 40 years old, of mixed race, housemaid, reported the onset of keratotic papules on the fourth and fifth right toes, with an ascending path towards dorsum of feet and anterior and medial face of right leg, since she was 12 (Figures 1 and 2). Clinical picture is asymptomatic, with no aggravating factors. She denies comorbidities. She has nine siblings and two daughters without similar lesions.

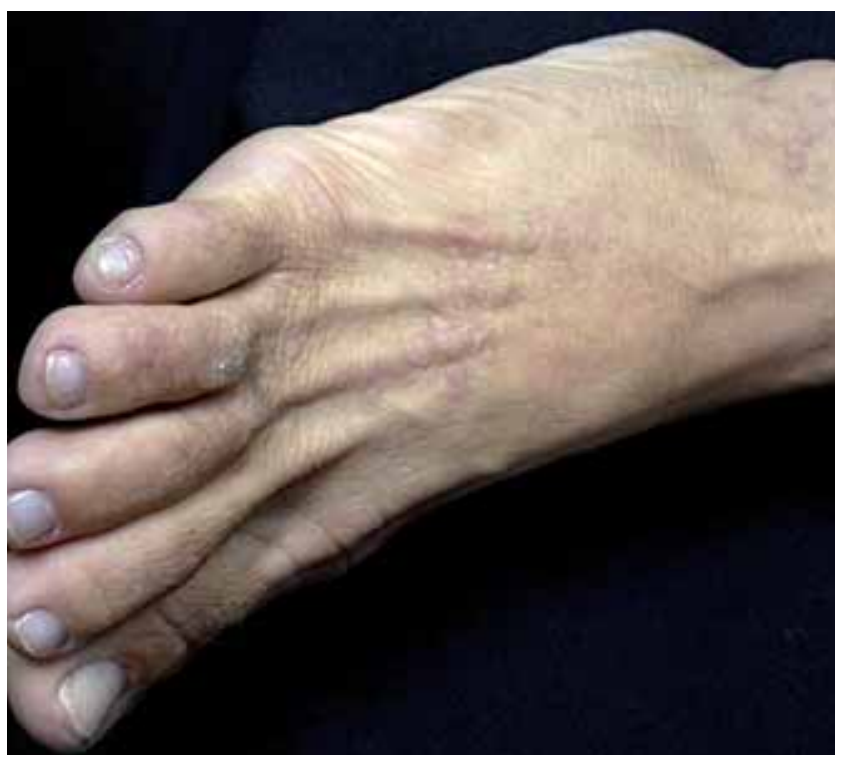

Figure 1: Grouped keratotic normochromic papules, with linear disposition on the dorsum of right foot

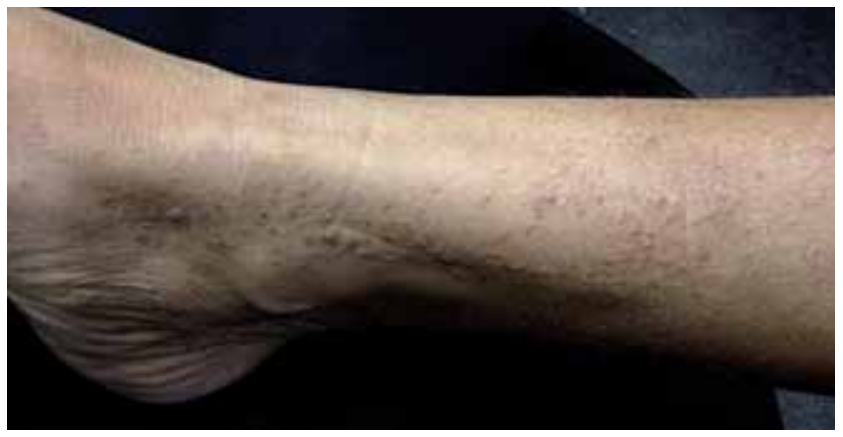

Figure 2: Erythematous and brownish keratotic papules grouped in a linear and ascending path on the anterior and medial face of right leg
At the histopathological examination, acantholysis and dyskeratosis were observed, compatible with segmental DD (Figure 3). Topical treatment with adapalene gel $0.3 \%$ was prescribed, associated with urea $20 \%$ and salicylic acid $8 \%$.

She has been under outpatient clinic follow-up for 6 months and, after 3 months of treatment, there was total remission of lesions on the leg and partial on dorsum of foot (Figures 4 and 5).

\section{DISCUSSION}

Type 1 phenotype of DD is the most common. 2,4,5 The skin surrounding the affected areas is normal. A post-zygotic somatic mutation would explain this variant. $^{5}$ If genetic mosaicism involve the gonads, the mutation may be transmitted to descendants and potentially result in widespread disease. ${ }^{4,5}$ In the case presented there was no similar history among siblings

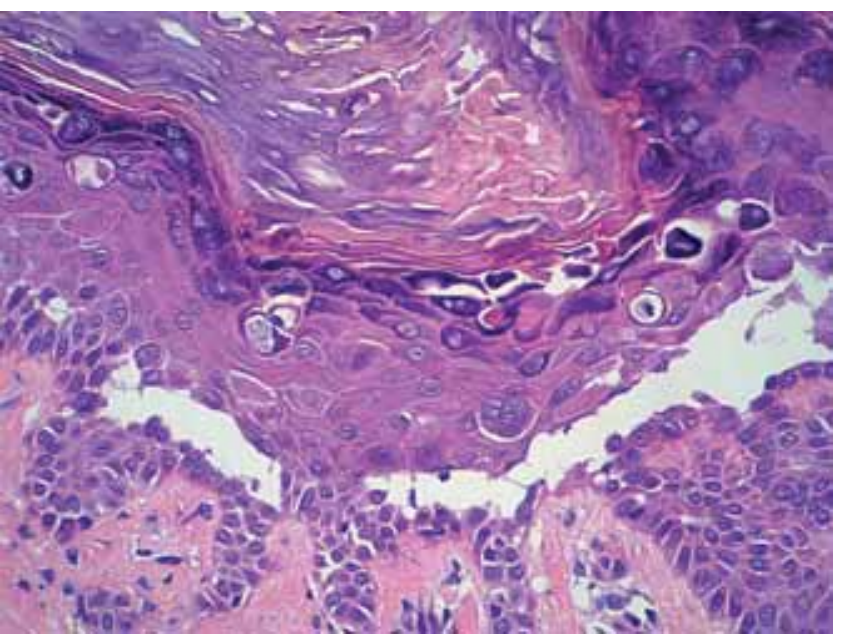

Figure 3: Histopathological section showing acantholysis and dyskeratosis, characterized by the presence of round bodies in the granular layer and grains in the corneal layer (HE - 200x)

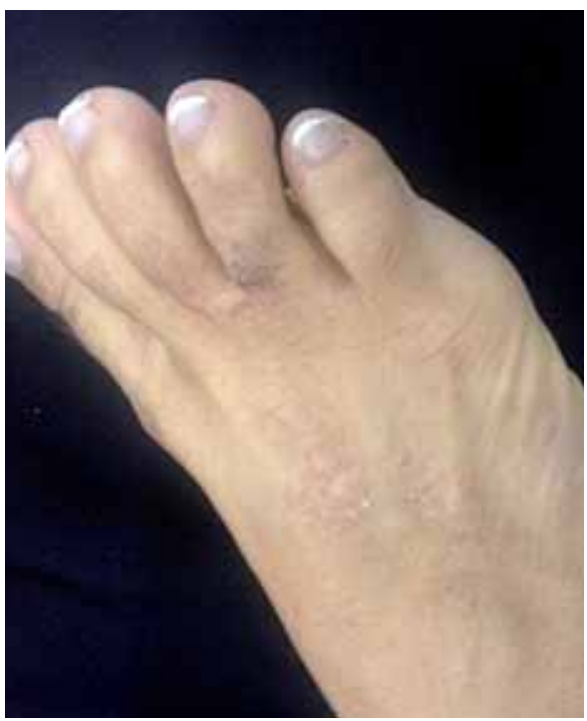

Figure 4: Partial improvement of cutaneous clinical picture demonstrated by the decreasing number of papules and keratotic aspect of lesion 


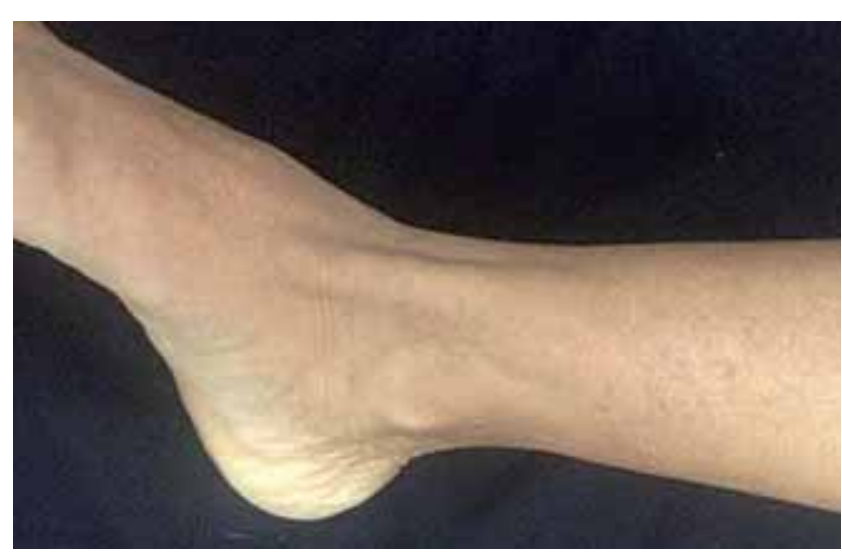

FiguRE 5: Complete resolution of lesions on the leg after topical treatment

and daughters, suggesting a post-zygotic mutation with no gonadal involvement. Histological findings do not differ from those of widespread disease. ${ }^{4}$

In type II variant, there is heterozygotic mutation in the germline associated with somatic loss of heterozygosity of the wild-type allele in a segmental area, which leads to homo or heterozygosity and then to an exponential increase in severity. ${ }^{2,4}$

The characteristics which accompany the widespread disease may be absent in the local ized forms. ${ }^{3,4}$ The average age in segmental cases presentation was estimated to be $27^{3}$; this is an older age group than the observed in the widespread disease. The patients frequently report the onset of lesions after sun exposure and exuberance with heat, perspiration and mechanical trauma, similar to what is observed in the widespread disease. ${ }^{5}$ However, the mentioned patient pre sented onset of lesions when she was 12 and denied aggravating factors.

Histopathological characteristics include dyskeratosis and acantholysis. Dyskeratosis is characterized by early keratinization cells with large basophilic nuclei in the granular (round bodies) and corneal (grains) layers. ${ }^{6}$ In these clefts originated by acantholysis, there are keratinocytes, either individual or in groups (acantholytic cells). Also observed are elongated buds and mild lymphocytic perivascular infiltrate in the superficial dermis. ${ }^{2,6}$
It is controversial to consider the localized DD form or some special form of epidermal nevi. ${ }^{7}$ The localized variant may be clinically and histologicaly indistinguishable from nevi with acantholytic dyskeratosis. $^{4}$

The hypothesis of nevus is supported by the absence of hereditary pattern, even though the course of segmental DD may happen without familial cases and be an underdiagnosed entity. ${ }^{3}$ The onset of late-age le sions corroborates the diagnosis of segmental DD. ${ }^{7}$

It is believed that the epidermal nevus with acantholytic dyskeratosis is a form of localized DD and it is suggested that its name be changed to segmental DD induced by post-zygotic mutation. ${ }^{4}$ Recent studies may lead to the conclusion that these two entities might be the same. ${ }^{2}$

Due to the low severity of the localized variant of DD, the treatment consists predominantly of topical therapy, besides behavioral measures such as avoiding triggering factors, wearing light clothing and sunscreen. ${ }^{5}$ Case reports have shown that topical retinoids (adapalene, tazarotene gel $0.01 \%$ and tretinoin) may reduce hyperkeratosis in 3 months, with irrigation being a limiting factor. Emolients, topical corticosteroids and reduction of retinoid concentration are options to alleviate the irritation. ${ }^{8}$ Some studies have demonstrated that tazarotene gel is superior to other topical treatments. ${ }^{5}$ Therapy with topical 5-fluorouracil has been effective in some patients. There are re ports of success with topical pimecrolimus. ${ }^{8}$ Bacterial colonization may be reduced with antiseptics and antibiotics. ${ }^{5}$

The established treatment took into account the easy access and low cost of chosen medications. Due to good therapeutic response and absence of adverse effects, the treatment was maintained.

The case reported confirms the need to place segmental DD, however rare, as a differential diagnosis of clinical lesions that follow Blaschko's lines, as well as verrucous epidermal nevus, striated lichen and linear lichen planus. The importance of histopathological exams in this diagnosis is also highlighted. $\square$ 


\section{REFERENCES}

1. Cooper SM, Burge SM. Darier's disease: epidemiology, pathophysiology and management. Am J Clin Dermatol. 2003;4:97-105.

2. Fraga CT. Enfermedad de Darier segmentaria tipo 2. Med Cutan Iber Lat Am 2009:37:262-5.

3. Reese DA, Paul AY, Davis B. Unilateral segmental Darier disease following blaschko lines: a case report and review of the literature. Cutis. 2005;76:197-200.

4. Gupta LK, Garg A, Khare AK, Mittal A. A case of zosteriform Darier's disease with seasonal recurrence. Indian Dermatol Online J . 2013;4:219-21.

5. Barfield RL, Barrett KR, Moon CM, David-Bajar K. Pruritic linear papules on a 75 year old woman: a case of localized Darier-White disease. Cutis. 2002;70:225-8.

6. Godié A. Darier disease. A review of pathophysiological mechanisms. Acta Dermatoven APA. 2003;12:119-26.

7. Sánchez Bermejo C, Fernández López E. A localized form of Darier's disease. Cutis. 2000;66:112-3.

8. emedicine.medscape.com [Internet]. Kwok PY, Wong JW, Bhutani T, Liao W, Taheri A, Talavera F, Feldman SR, Gelfand J M, Elston DM. Keratosis follicularis (Darier Disease) treatment \& management. [cited 2014 Mar 9]. Available from: http://emedicine.medscape.com/article/1107340-treatment
M AILING ADDRESS:

Paula M ota M edeiros

A lameda Jauaperi, 887, apto 124, M oema

CEP: 04523-014 - São Paulo - SP

Brazil

E-mail: paula_mota@hotmail.com

How to cite this artide: Medeiros PM, Alves NRM, Trujillo JM, Silva CC, Faria PCP, Silva RS. Segmental Darier disease: a presentation of difficult diagnosis. An Bras Dermatol. 2015;90 (3 Suppl 1): S62-5. 